УДК 552.5(263.53)

\title{
ЛИТОЛОГИЧЕСКИЕ ОСОБЕННОСТИ И ОРГАНИЧЕСКОЕ ВЕЩЕСТВО ОСАДОЧНЫХ ОТЛОЖЕНИЙ ЮГО-ВОСТОЧНОЙ ЧАСТИ МОРЯ ЛАПТЕВЫХ (МЫС МУОСТАХ)
}

\author{
Перевертайло Татьяна Геннадьевна', \\ ptg@tpu.ru
}

Кажумуханова Малика Зейнеллаевна², kazhumukhanova@gmail.com

\author{
Недоливко Наталья Михайловна', \\ nedolivko@tpu.ru
}

\author{
Гринько Андрей Алексеевич', \\ grinko@tpu.ru
}

\author{
Дударев Олег Викторович ${ }^{3,1}$ \\ dudarev@poi.dvo.ru
}

Гершелис Елена Владимировна', elenapanova@tpu.ru

\author{
Мазуров Алексей Карпович', \\ akm@tpu.ru
}

\section{Семилетов Игорь Петрович ${ }^{3,1}$, ipsemiletov@alaska.edu}

\author{
Шахова Наталья Евгеньевна', \\ shahova@tpu.ru \\ 1 Национальный исследовательский Томский политехнический университет, \\ Россия, 634050, г. Томск, пр. Ленина, 30. \\ 2 ТОО «Казцинк», \\ Республика Казахстан, г. Кокшетау, ул. Абая, 96. \\ з Тихоокеанский океанологический институт им. В.И. Ильичева Дальневосточного отделения Российской Академии наук, \\ Россия, 690041, г. Владивосток, ул. Балтийская, 43.
}

\begin{abstract}
Актуальность исследования продиктована необходимостью изучения современных изменений климата, которые рассматриваются как последствия парникового эффекта, обусловленного ростом содержания в атмосфере основных парниковых газов двуокиси углерода и метана. Для изучения этой проблемы и построения модели климата необходимо проведение комплексных исследований в системе суша-шельф-атмосфера на Арктическом шельфе, включая оценку потенциала морей Восточной Арктики в контексте особенностей литологического состава и трансформации органического вещества в углеводороды в процессе диагенетических и катагенетических преобразований.

Цель: изучение литологического и минералогического составов, изменчивости содержания органического вещества $\left(C_{\text {орг }}\right)$, молекулярного и изотопного состава углерода ( $\delta 13 C)$ в отложениях ледового комплекса побережья моря Лаптевых (мыс Муастах). объект: пробы современных донных осадков, отобранных в ходе проведения экспедиционных работ 2015 г. в юго-восточной части моря Лаптевых.

Методика исследования донных отложений включает в себя пробоподготовку, лабораторно-аналитические исследования (хроматомасс-спектрометрия, пиролиз, изотопия, рентгенофазовый анализ, методы обработки и интерпретации результатов). Результаты. Изучен минералогический состав глинистой фракции, установлена зональность распределения глинистых минералов. Выявлены особенности состава органического вещества на молекулярном и изотопном уровнях. Получены первые результаты по потенциалу генерации углеводородов из органического вещества осадков ледового комплекса, которые доминируют в мелководной части Восточно-Сибирского шельфа. Результаты исследований, полученные по данным пиролиза и хроматомассспектрометрии, имеют высокую степень корреляции и отражают комплекс биохимических процессов, сопровождающих превращение органического вещества на различных стадиях литогенеза. Кроме того, приведены первые оценки потенциала генерации легких углеводородов из Сог исследуемых осадков.
\end{abstract}

\section{Ключевые слова:}

Органическое вещество, донные осадки, изотопный анализ, хроматомасс-спектрометрия, минералогический состав, море Лаптевых, мыс Муостах.

\section{Введение}

В настоящее время современные изменения климата рассматриваются как последствия парникового эффекта, обусловленного ростом содержания в атмосфере основных парниковых газов двуокиси углерода и метана $\left(\mathrm{CO}_{2}\right.$ и $\left.\mathrm{CH}_{4}\right)[1,2]$. Ocновным источником $\mathrm{CO}_{2}$ является аэробное окисление органического вещества (OB), a $\mathrm{CH}_{4}$ - деградация подводной мерзлоты, дестабилизация метановых гидратов и мобилизация глубинных, возможно, абиогенных источников $\mathrm{CH}_{4}$ [3-8].
Показано, что моря Восточной Арктики (МВА) являются источником метана в атмосферу Арктического региона, вклад которого соизмерим с вкладом всего Мирового океана и обусловлен деградацией подводной мерзлоты $[7,9,10]$. Проведенные ранее исследования $[5,6]$ выявили на территории моря Лаптевых около 200 мощных факелов с рекордно высокой концентрацией метана (до 6000 нМ). Комплексные гидроакустические и гидрофизические исследования позволили идентифицировать корни факелов пузырькового метана в 
толще донных отложений, обогащенных ОВ. Дальнейшие диагенетические и катагенетические трансформации ОВ приводят к формированию гигантского углеводородного пула на шельфе MBA [5, 6], который вовлекается в современные биогеохимические и климатические процессы через таликовые зоны, формирующиеся в результате деградации подводной мерзлоты [3, 7, 9-11].

Исследования последних 20 лет подтвердили гипотезу о том, что основным источником $\mathrm{CO}_{2}$ на шельфе МВА является окисление эрозионного углерода ледового комплекса (ЛК) прибрежной мерзлоты, что приводит к ряду экологических проблем, обусловленных экстремальной асидификацией вод MBA [12-15]. Было показано, что эрозионный углерод ЛК определяет современный осадочный и биогеохимический режим от прибрежной зоны до изобаты примерно $40 \mathrm{~m}$ - более 70 \% акватории MBA $[15,16]$. Более того, прогрессирующая деградация подводной мерзлоты, которая содержит фрагменты погребенного ЛК, может привести к значительному увеличению эмиссии $\mathrm{CH}_{4}$ за счет формирования открытых таликов [3, 9-11, 17].

Предполагается, что дальнейшее потепление климата и увеличение жидкого и твердого материкового стока, а также прогрессирующая деградация наземной и подводной мерзлоты приведут к усилению атмосферной эмиссии парниковых газов $\left(\mathrm{CO}_{2}\right.$ и $\left.\mathrm{CH}_{4}\right)[1,3]$, в особенности - к усилению массированного выброса $\mathrm{CH}_{4}[3,6,12]$. Для изучения этой проблемы и построения модели климата необходимо проведение более комплексных исследований в системе суша-шельф-атмосфера на Арктическом шельфе, включая оценку потенциала MBA в контексте особенностей литологического состава и трансформации органического вещества в углеводороды в процессах диагенетических и катагенетических трансформаций [7, 17-23].

\section{Цель и объект исследования}

Основной целью данной работы являлось изучение литологического и минералогического составов, изменчивости содержания органического вещества $\left(C_{\text {орг }}\right)$, молекулярного и изотопного состава углерода $\left(\delta^{13} \mathrm{C}\right)$ в отложениях ЛК побережья моря Лаптевых. Кроме того, приведены первые оценки потенциала генерации легких углеводородов из $C_{\text {орг }}$ исследуемых осадков МВА.

Представлены результаты лабораторно-аналитических исследований проб современных осадков, отобранных в ходе проведения экспедиционных работ 2015 г. в юго-восточной части моря Лаптевых (рис. 1).

Высокая скорость береговых эрозионных процессов, которая проявляется в экспорте огромного количества эрозионного $C_{\text {орг }}$ на шельфе MBA, обусловила необходимость проведения более детальных работ, направленных на понимание исходного (end-member) литологического, молекулярного и изотопного состава, а также углеводородного потенциала $C_{\text {орг }}$ образцов осадочного материала, отобранных вдоль разреза сверху вниз по клифу мыса Муостах Быковского полуострова, в конусе выноса и волноприбойной нише.

\section{Методика исследований}

Методика исследований донных отложений включает в себя пробоподготовку, лабораторноаналитические исследования, методы обработки и интерпретации результатов.

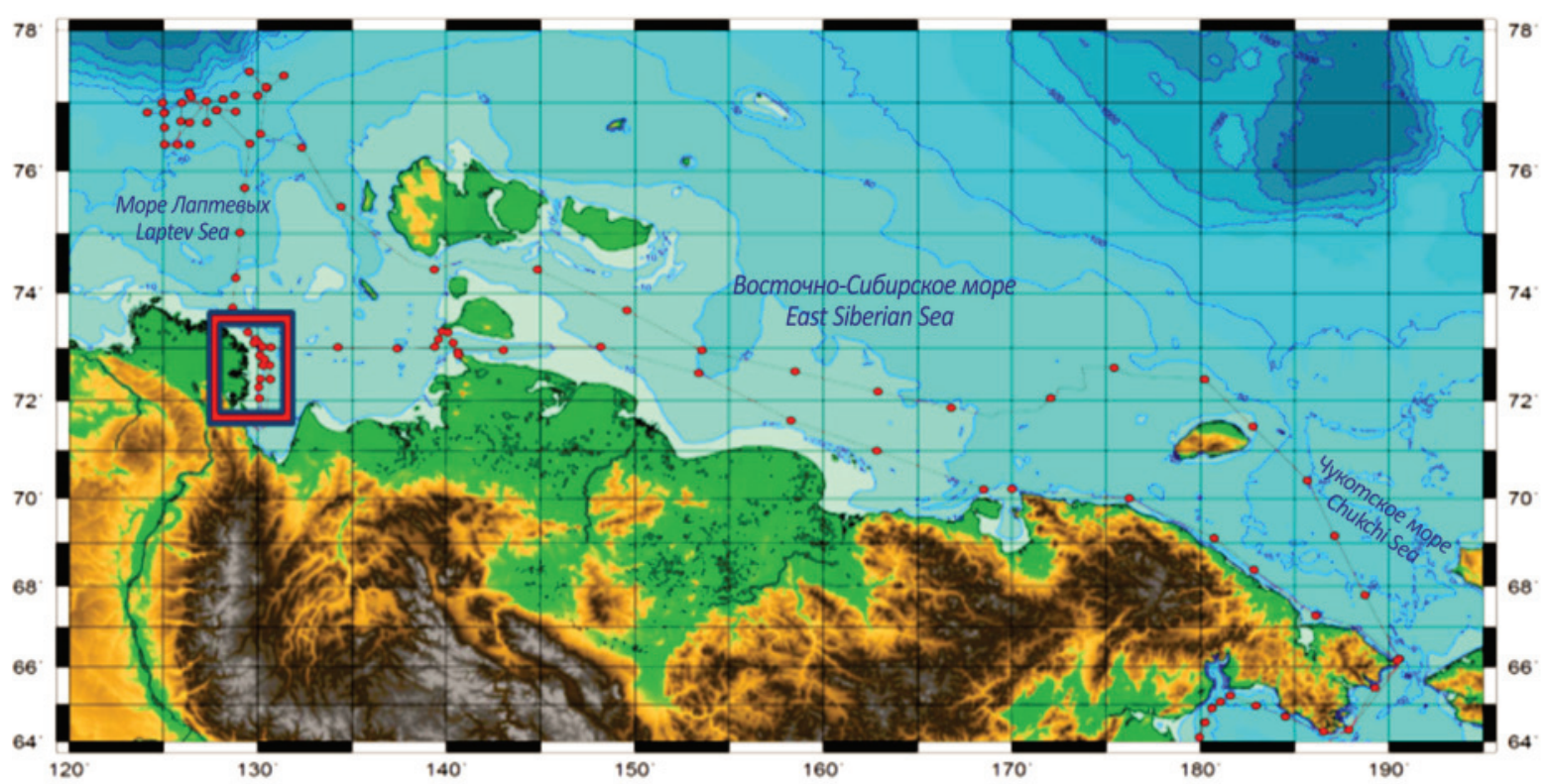

Рис. 1. Район исследований. Район работ выделен в красный квадрат. Красныли точками показано положение океанологических станиий с отбором образиов осадков для дальнейших исследований

Fig. 1. Study area. Sampling area for the present study is highlighted with the red square. Red dots indicate sampling stations for further studies not included in the present paper 
Отобранные образцы хранили при $t=-18^{\circ} \mathrm{C}$.

1. На этапе пробоподготовки проводилось размораживание образцов при комнатной температуре в течение суток, гомогенизация, доведение образцов до постоянного веса в сушильном шкафу при $t=+45{ }^{\circ} \mathrm{C}$ и экстрагирование хлороформом в аппарате Сокслета в течение 14 ч. Далее экстракты концентрировались на роторном испарителе и сушились до постоянного веса.

Полученные экстракты исследовали методом хроматомасс-спектрометрии (XMC) на приборе SCION 436 GC TQ фирмы «Bruker» с использованием кварцевой капиллярной колонки HP-5MS (длина 30 м, внутренний диаметр 0,25 мм, толщина пленки 0,25 мкм). Условия анализа: Температура испарителя $300{ }^{\circ} \mathrm{C}$, температурная программа - начальная $t=+40{ }^{\circ} \mathrm{C}$, нагрев $5^{\circ} \mathrm{C} /$ мин до $150^{\circ} \mathrm{C}$, $3{ }^{\circ} \mathrm{C} /$ мин до $310{ }^{\circ} \mathrm{C}$, выдержка при $310{ }^{\circ} \mathrm{C}-20$ мин. Скорость газа-носителя (гелий) - 1,1 мл/мин, объем вводимой пробы - 1 мкл (растворитель гексан). Измерения проводились как по полному ионному току, так и по выбранным ионам (в режимах Scan и SIM), а также в режиме MS-MS на приборе GCMS Agilent 7890B (GC) - Agilent Q-TOF 7200 (MS) при той же температурной программе (колонка кварцевая капиллярная HP-1MS, длина 30 мм, внутренний диаметр 0,25 мм, толщина фазы 0,25 мкм) с вторичной ионизацией в ячейке соударения с азотом при энергии соударения 15 эВ. Дополнительно на SCION 436 GC TQ для подтверждения результатов идентификации отдельных соединений хроматограммы образцов снимались в режиме MRM с вторичной ионизацией в ячейке coyдарения с аргоном, контролировались переходы $\mathrm{M}+=410,412$ a. е. $\mathrm{M} \rightarrow 81,69,95,121,137,189$, $190,191,192$.

Идентификация компонентов осуществлялась по масс-спектрометрическим библиотекам NIST 14 , а также по детальному изучению масс-спектра осколочных и молекулярных ионов с использованием справочной литературы по масс-спектрометрии, paнее проанализированных в лаборатории образцов экстрактов пород и нефтей, а также стандартов, предоставленных фирмой Chiron. Относительные концентрации компонентов определяли методом внутренней нормализации [24-29].

2. Определение общего содержания органического углерода, легколетучих органических соединений в осадках. Исследования проводились в Международной научно-образовательной лаборатории изучения углерода арктических морей Томского политехнического университета на пиролизаторе «Rock-Eval 6 Turbo» VINCI Technologies. Старт нагрева образца - $300{ }^{\circ} \mathrm{C}$, выдержка 3 мин, далее нагрев до $650{ }^{\circ} \mathrm{C}$ со скоростью $25{ }^{\circ} \mathrm{C} /$ мин [30-32].

3. Определение изотопного состава органического углерода в декарбонатизированных образцах донных отложений проводили на изотопном масс-спектрометре DELTA V ADVANTAGE (производитель «Thermo Fisher Scientific») в лаборатории геохимии и пластовых нефтей ОАО «ТомскНИПИнефть» (г. Томск).

4. Минералогический состав глинистой фракции изучался методом рентгеновской дифракции (РФА). Процедура проведения РФА состоит из следующих этапов:

- подготовка образцов для съемки дифрактограмм;

- съёмка и запись дифрактограмм;

- качественная и количественная интерпретация дифрактограмм.

Для анализа глинистых минералов пробоподготовка, заключающаяся в выделении пелитовой фракции (<5 мкм) из основной массы породы, производится в несколько этапов:

- механическое дробление образцов на щековой дробилке Fritsch «Pulverisette 1»;

- ручное щадящее дробление в фарфоровой или металлической ступке;

- мокрое просеивание полученной пробы через сито с размером ячеек 0,10 или 0,25 мм в зависимости от её зернистости для удаления крупных частичек;

- тщательное перемешивание (гомогенизация) пробы;

- перетирание пробы в фарфоровой ступке с удалением насыщенной суспензии в отдельный стакан;

- обработка суспензии ультразвуком при частоте 22 кГц в течение 5 минут с целью выделения тонких фракций из песчано-глинистой породы, а также очистки поверхности зерен от различных примазок и загрязнений;

- диспергация суспензии смесью пирофосфата натрия, соды и добавок ПАВ, что обеспечивает получение глинистой суспензии высокого качества. Разбавление суспензии дистиллированной водой и отстаивание раствора в течение суток. Если столб воды прозрачный - процедура повторяется до тех пор, пока столб воды станет непрозрачный;

- центрифугирование взятой фракции для консолидации твёрдой части суспензии;

- помещение полученной суспензии в выпарные фарфоровые чашки и высушивание в сушильном шкафу при $t=+45{ }^{\circ} \mathrm{C}$ или при комнатных условиях.

- пакетирование полученной пробы для дальнейшего хранения.

Съёмка дифрактограмм проводится при следующих параметрах: анод - $\mathrm{Cu}$ (медь), напряжение рентгеновской трубки - $40 \mathrm{\kappa B}$, ток - $30 \mathrm{мA}$, мощность - 1,2 кВт, скорость съемки $1 \%$ мин, шаг $0,02^{\circ}$, углы съемки $2 \Theta$ от $3^{\circ}$ до $65^{\circ}$.

Интерпретация дифрактограмм включает в себя следующие операции: идентификация фазового состава исследованного образца путем сопоставления наблюдаемого набора углов дифракционных максимумов или набора межплоскостных расстояний с данными компьютерных баз данных; построение моделей кристаллической структуры для 
всех установленных кристаллических фаз; симуляция суммарной дифракционной картины для всех обнаруженных фаз; расчет количественного содержания фаз в образце с использованием метода полнопрофильного анализа [33-35].

\section{Результаты исследований}

Согласно данным РФА, основу минералогического состава отложений составляют каркасные минералы - кварц и полевые шпаты (рис. 2), содержание которых достигает 71,9...82,7 \% . Полевые шпаты в изученных образцах представлены в основном плагиоклазами, тогда как калиевый полевой шпат присутствует в осадках в незначительных количествах. Доля калиевых полевых шпатов составляет в среднем около $6 \%$, плагиоклазов - $26 \%$, при общем содержании полевых шпатов до $36 \%$.

В осадках присутствуют гидрослюды группы мусковита (иллит-мусковит) - самого стойкого к выветриванию слоистого силиката, содержание которого в среднем составляет $14,6 \%$.

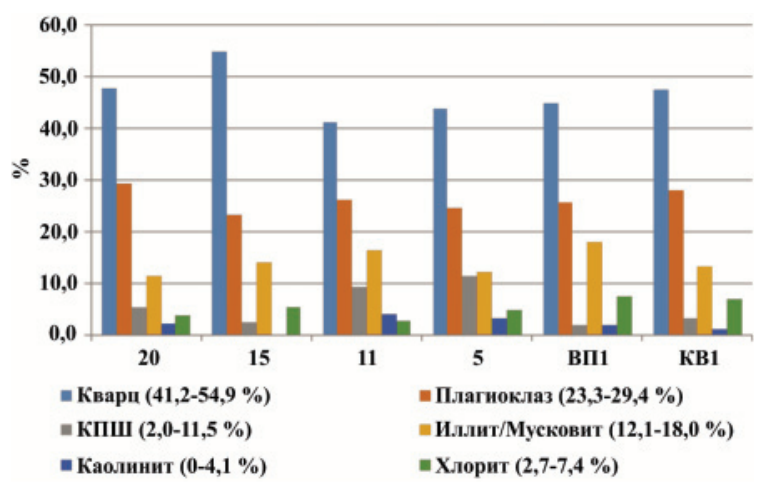

Pис. 2. Общий минералогический состав осадочного материала мысаса Myостаx

Fig. 2. Total mineralogical composition of the surface sediments (Cape Muostakh)

Глинистые минералы (рис. 3) представлены каолинитом, хлоритом и иллитом и их содержание в осадочном материале не превышает $27 \%$. Смешаннослойные образования обнаружены в образцах, отобранных на абсолютных отметках 20, 11 м, волноприбойной нише и конусе выноса.

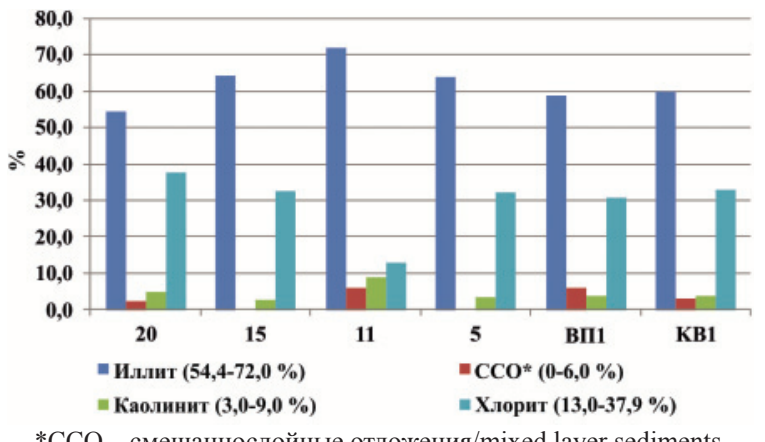

*CCO - смешаннослойные отложения/mixed layer sediments

Pис.3. Содержание глинистых минералов в отложениях мыса Myocmax

Fig. 3. Clay minerals content in the surface sediments (Cape Muostakh)
В горизонтах с уменьшением суммарного содержания глинистых минералов происходит увеличение содержания кварца и резкое уменьшение относительного содержания каолинита и, наоборот, - с увеличением доли глинистых минералов наблюдается уменьшение содержания кварца, а среди глинистых минералов возрастает количество каолинита.

Зональность глинистых минералов заключается в следующем: вниз по разрезу уменьшается доля хлорита, возрастает количество иллита, каолинита и смешаннослойных образований, достигая максимальных концентраций на высоте 11 м, что указывает на континентальный генезис осадконакопления.

Содержание $\delta^{13} \mathrm{C}$ в исследуемых образцах варьирует в широких пределах (от -23 до -28 \%о ). Отложения, залегающие на абсолютной высоте от 5 до 15 м, обладают более тяжелым изотопным составом $\left(\delta^{13} \mathrm{C}\right.$ от -23 до $\left.-24 \%\right)$. Низкие значения $(-27,2 \% ;-28 \%$ ) характерны для образцов с высоким содержанием $C_{\text {орг }}$ (табл. 1$)$.

Tаблииа 1. Геохимические коэффициенты и данные Rock-Eval анализа осадочного материала

Table 1. Rock-Eval analysis data and relevant geochemical indexes

\begin{tabular}{|c|c|c|c|c|c|c|c|c|}
\hline \multirow{3}{*}{$\begin{array}{l}\text { № образца } \\
\text { Sample no. }\end{array}$} & \multicolumn{7}{|c|}{ Параметры Rock-Eval/Rock-Eval ratios } & \multirow{3}{*}{$\begin{array}{c}\delta^{13} \mathrm{C} \\
\% 0\end{array}$} \\
\hline & S1 & $\mathrm{S} 2$ & S3 & $\mathrm{HI}$ & OI & MinC & TOC & \\
\hline & \multicolumn{5}{|c|}{$\mathrm{мг} / \Gamma / \mathrm{mg} / \mathrm{g}$} & \multicolumn{2}{|c|}{$\%$ mac. $/ \%$ wt. } & \\
\hline 21,5 & 36,13 & 104,94 & 70,34 & 307 & 206 & 1,61 & 34,15 & $-28,00$ \\
\hline 20 & 5,20 & 15,74 & 6,78 & 294 & 127 & 0,22 & 5,35 & $-27,20$ \\
\hline 15 & 0,19 & 2,21 & 3,26 & 109 & 161 & 0,18 & 2,02 & $-24,30$ \\
\hline 11 & 0,13 & 1,39 & 2,62 & 81 & 152 & 0,15 & 1,72 & $-24,30$ \\
\hline 5 & 0,02 & 0,14 & 0,99 & 15 & 103 & 0,11 & 0,96 & $-23,60$ \\
\hline ВП1 & 0,57 & 5,14 & 4,30 & 187 & 156 & 0,17 & 2,75 & $-26,20$ \\
\hline KB1 & 0,50 & 3,84 & 4,67 & 131 & 159 & 0,22 & 2,94 & $-27,60$ \\
\hline
\end{tabular}

Примечание: ТОС - total organic carbon (количество органического углерода ), \% мас.; $S 1$ - количество летучих $\left(300^{\circ} \mathrm{C}\right)$ органических соединений, мг/г породы; $S 2$ - количество летучих продуктов деструкции органического вещества, мг/г породы; HI - водородный индекс $S 2 \times 100 / T O C$, мг продуктов деструкиии/г органического углерода; МіпC - содержание минерального углерода, \% мас.

Note: TOC is the total organic carbon (amount of organic carbon), \% by weight; $S 1$ is the amount of volatile $\left(300^{\circ} \mathrm{C}\right)$ organic compounds, $\mathrm{mg} / \mathrm{g}$ of rock; $\mathrm{S} 2$ is the amount of volatile organic matter degradation products, $\mathrm{mg} / \mathrm{g}$ of rock; HI is the hydrogen index $\mathrm{S} 2 \times 100 / \mathrm{TOC}, \mathrm{mg}$ of degradation products/g of organic carbon; MinC is the mineral carbon content, $\% w t$.

Содержание $C_{\text {орг }}$ в исследованных пробах изменялось в пределах от 0,9 до $34,1 \%$, с содержанием летучих органических соединений (S1) от 0,02 до 36,13 мг/г породы.

Содержание высокомолекулярных органических веществ и соединений, образующихся в результате крекинга (S2) изменяется в широком интервале от 0,14 до 104,94 мг/г и содержание $\mathrm{CO}_{2}$ при крекинге остаточного органического вещества (S3) варьирует от 0,99 до 70,34 мг/г породы.

Таким образом, количество летучих органических соединений (количественно равное экстрагируемой части органического вещества породы - параметр S1) в осадках относительно невелико по 
сравнению с продуктами высокотемпературной деструкции органического вещества (параметр S2). Можно заключить, что основная масса органического вещества представлена высокомолекулярными нелетучими соединениями - биогеополимеpom.

Распределение суммарных показателей углеводородов (S1, S2, S3) в исследуемых пробах идентично распределению ТОС (рис. 4), что подтверждается высокими положительными значениями коэффициента корреляции между S1, S2, S3 и ТOC (табл. 2).

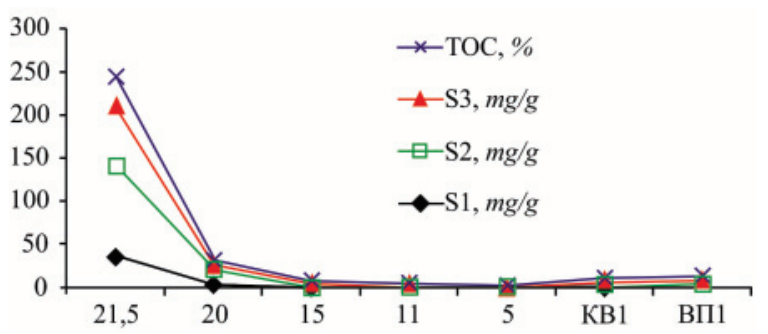

Puc. 4. Распределение сумларных показателей S1, S2, S3, TOC в пробах осадочного материала мыса Муостах

Fig. 4. Distribution of S1, S2, S3, TOC indices in sediments samples
Таблица 2. Значения коэффициентов парной корреляции между основными параметрами анализа Rock-Eval

Table 2. Correlation ratios for the basic Rock-Eval parameters

\begin{tabular}{|c|c|c|c|c|}
\hline Параметры/Ratios & S1 & S2 & S3 & TOC \\
\hline S1 & 1,0 & 0,9996 & 0,9959 & 0,9985 \\
\hline S2 & 0,9996 & 1,0 & 0,9970 & 0,9994 \\
\hline S3 & 0,9959 & 0,9970 & 1,0 & 0,9988 \\
\hline TOC & 0,9985 & 0,9994 & 0,9988 & 1,0 \\
\hline
\end{tabular}

Однако количественные соотношения индексов НІ и ОІ в исследуемых пробах отличаются. В образцах, отобранных с абсолютных отметок (а. о.) в 21,5 и 20 м, высокий водородный индекс, следовательно, в нерастворимом органическом веществе (керогене) преобладают водородонасыщенные фрагменты, и их образование проходило в более восстановительной среде. В нижележащих отложениях клифа мыса Муостах более высокий кислородный индекс, следовательно - в керогене преобладают кислородные структуры, и осадконакопление проходило в более окисленной среде.

По полученным данным литологического анализа построен сводный геологический разрез обнажения мыса Муостах (рис. 5, a) и распределения органического вещества (ТОС), органических сое-

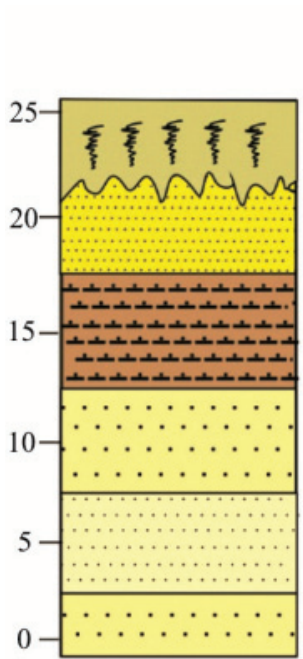

a)
TOC, \%
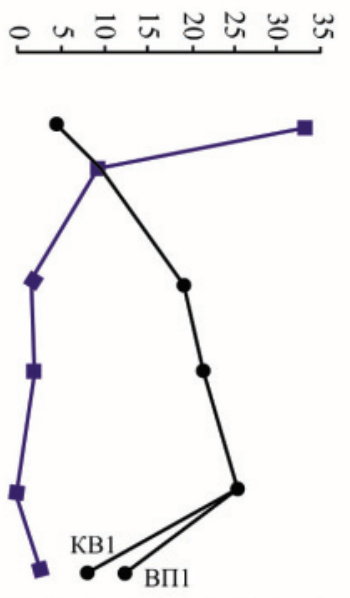

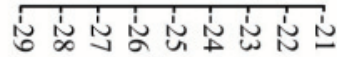
$\delta^{13} \mathrm{C}, \%$
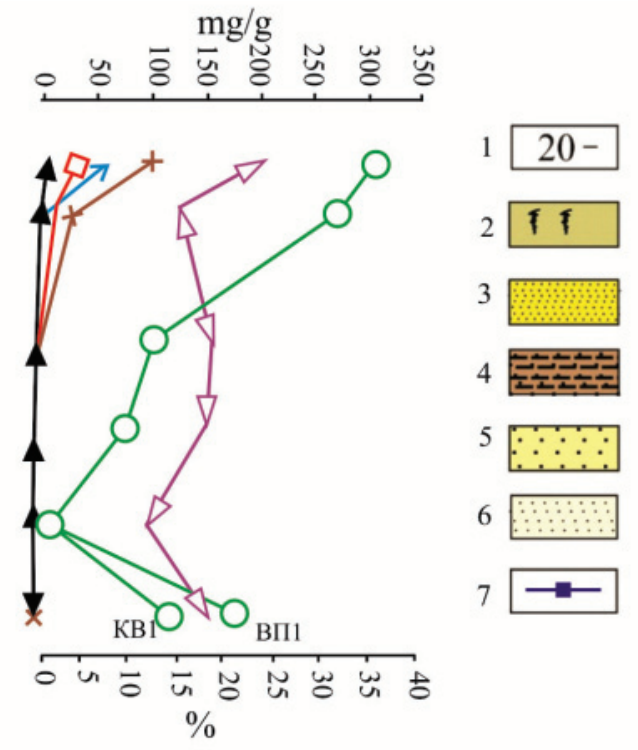

8 $9 \longrightarrow$

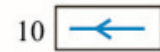
$1 1 \longdiv { - }$ $12-\mathrm{O}$ $1 3 \longdiv { - }$

14

b)

Pис.5. Распределение органического углерода по разрезу ледового колплекса мыса Муостах: а) литологическая колонка; $b$ ) данные Rock-Eval анализа исследуелых проб. Условные обозначения: 1 - абсолютная высота над уровнем моря, м; 2 - дерново-торфяной покров; 3 - песок мелкозернистый; 4 - алеврит пелитовый; 5 - песок крупнозернистый; 6 - песок среднезернистый; 7 - распределение общего содержания органического углерода (ТОC, \%); 8 - S1- количество летучих (300 $\left.{ }^{\circ} \mathrm{C}\right)$ органических соединений, мг/г породы; 9 - S2 - количество летучих продуктов деструкции органического вещества, мг/г породы; 10 - S3 - количество СО, выделившегося при пиролизе керогена и при низкотемпературном (<600 ${ }^{\circ} \mathrm{C}$ ) разложении карбонатов, мг СО/г породы; 11 HI - водородный индекс S2·100/TOC, лг продуктов деструкиии/г органического углерода; 12 - ОI - кислородный индекс, мг СО/г $C_{\text {орг }} ; 13$ - МіпC - содержание минерального углерода, \% мас.; 14 - распределение изотопного состава органического углерода $\left(\delta^{13} \mathrm{C}, \%\right.$ )

Fig. 5. Distribution of organic carbon through the ICD cross-section (Cape Muostakh): a) lithological column; b) Rock-Eval analysis data. 1 is the absolute altitude above sea level, $m$; 2 is the sod-peat cover; 3 is the fine-grained sand; 4 is the pelitic silt; 5 is the coarse-grained sand; 6 is the medium-grained sand; 7 is the distribution of total organic carbon (TOC, \%); $8-S 1$ is the amount of volatile (300 ${ }^{\circ} \mathrm{C}$ ) organic compounds, $\mathrm{mg} / \mathrm{g} ; 9$ - S2 is the amount of volatile organic matter degradation products, $\mathrm{mg} / \mathrm{g} ; 10$ - S3 is the amount of CO released during kerogen pyrolysis and low temperature $\left(<600^{\circ} \mathrm{C}\right)$ carbonates decomposition, $\mathrm{mg} \mathrm{CO} / \mathrm{g} ; 11-\mathrm{HI}$ is the hydrogen index $\mathrm{S} 2 \cdot 100 / \mathrm{TOC}$, $m g$ of degradation products $/ \mathrm{g}$ of $\mathrm{C}_{\mathrm{org}} ; 12-\mathrm{OI}$ is the oxygen index, $\mathrm{mg} \mathrm{CO} / \mathrm{g} \mathrm{C}_{\mathrm{org}} ; 13-\mathrm{MinC}$ is the mineral carbon content by weight; 14 is the organic carbon isotope composition $(\delta 13 C, \%$ ) 
динений и изотопного состава органического углерода $\left(\delta^{13} \mathrm{C}\right)$ (рис. $\left.5, b\right)$.

Максимальные значения всех исследуемых параметров зафиксированы в верхней части разреза, представленной торфяником, затем исходные значения содержания $C_{\text {орг }}$ к средней части разреза уменьшаются в среднем в 20 раз, на пляже - еще почти в 2 раза, при результирующем сокращении до 37 раз. Содержание органического углерода в отложениях клифа резко увеличивается к конусу выноса и волноприбойной нише, в которой отмечается наличие растительных остатков, вероятнее всего, накопившиеся в результате сползания материала с более молодых, верхних горизонтов разреза вследствие процессов эоловой эрозии и термоабразии [36-38].

Образец, отобранный на а.о. 5,0 м, по многим параметрам характеризуется аномальными значениями параметров (табл. 1,3 , рис. 5-8), что свидетельствует о высокой степени преобразованности его органического вещества. Этот образец обладает низким водородным индексом и тяжелым изотопным составом, что обусловлено потерей в процессе окисления изотопно-лёгких алифатических углеводородных фрагментов в его составе. В составе органического вещества этого образца отсутствуют алкены, тогда как на остальных горизонтах они присутствуют, в том числе в волноприбойной нише. Накопление органического вещества происходило в восстановительных условиях. Отсутствие алкенов, а также минимальное значение параметра $\mathrm{C} / \mathrm{D}$, характеризующего вклад низкомолекулярных алканов, по-видимому, свидетельствуют о минимальной бактериальной активности на этом уровне клифа.

Таблица 3. Геохимические коэффициенты, рассчитанные на основе ХMC данных

Table 3. Geochemical ratios based on GC-MS data

\begin{tabular}{|c|c|c|c|c|c|}
\hline № образца/Sample no. & $\mathrm{Pr} / \mathrm{Phy}$ & $\mathrm{Ki}$ & $\mathrm{A} / \mathrm{B}$ & $\mathrm{C} / \mathrm{D}$ & $\mathrm{CPI}$ \\
\hline 21,5 & 1,30 & 0,50 & 0,19 & 0,16 & 6,94 \\
\hline 20 & 0,78 & 0,27 & 0,28 & 0,07 & 7,17 \\
\hline 15 & 1,20 & 0,34 & 0,18 & 0,06 & 9,19 \\
\hline 11 & 1,01 & 0,47 & 0,31 & 0,15 & 7,55 \\
\hline 5 & 0,38 & 0,52 & 0,44 & 0,03 & 3,94 \\
\hline ВП1 & 1,02 & 0,30 & 0,34 & 0,07 & 6,66 \\
\hline КВ1 & 1,31 & 0,36 & 0,22 & 0,08 & 7,18 \\
\hline
\end{tabular}

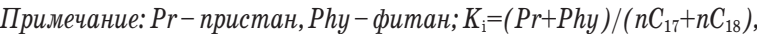
$A / B$ - отношение сулмы площадей пиков н-алканов по четной огибающей к сумме площадей пиков высокомолекулярных н-алканов - маркеров высшей назелной растительности по $\mathrm{m} / z$ 57, $C / D$ - отношение сумлы площадей пиков низкомолекулярных налканов к сулле пиков высокомолекулярных алканов по четной огибающей no $\mathrm{m} / z \quad 57, \quad C P I=0,5 *\left[\left(C_{25}+C_{27}+C_{29}+C_{31}+C_{33}\right) /\right.$ $\left.\left(C_{24}+C_{26}+C_{28}+C_{30}+C_{32}\right)+\left(C_{25}+C_{27}+C_{29}+C_{31}+C_{33}\right) /\left(C_{26}+C_{28}+C_{30}+C_{32}+C_{34}\right)\right]$.

Note: $P r$ - Pristane, Phy - Phytan; $K_{\mathrm{i}}=(P r+P h y) /\left(n C_{17}+n C_{18}\right), A / B-$ ratio of the sum of n-alkanes peaks areas over the "even envelope» to the sum of high molecular n-alkanes peaks areas - markers of higher terrestrial vegetation $(\mathrm{m} / \mathrm{z} 57), \mathrm{C} / \mathrm{D}$ - the ratio of the sum of low-molecular $n$-alkanes peaks areas to the sum of high-molecular alkanes peaks over an «even envelope» $(\mathrm{m} / z 57), C P I=0,5 *\left[\left(C_{25}+C_{27}+C_{29}+C_{31}+C_{33}\right) /\right.$ $\left.\left.C_{24}+C_{26}+C_{28}+C_{30}+C_{32}\right)+\left(C_{25}+C_{27}+C_{29}+C_{31}+C_{33}\right) /\left(C_{26}+C_{28}+C_{30}+C_{32}+C_{34}\right)\right]$.
Проведен корреляционный анализ коэффициентов, полученных по данным пиролиза и ХMC (зависимость коэффициентов $\mathrm{Pr} / \mathrm{Phy}, \mathrm{OI}$ и $\mathrm{A} / \mathrm{B}, \mathrm{HI}$ и $\left.\delta^{13} \mathrm{C}\right)$, и установлена хорошая сопоставимость результатов, полученных разными методами (рис. 6,7$)$. Как видно из графиков, по мере распределения исследуемых параметров вниз по разрезу происходит преобразование исходного вещества под действием различных биохимических процессов. Так, близкие к исходной биомассе и, следовательно, подвергшиеся наименьшим изменениям образцы расположены на горизонтах, близких к торфяному слою (рис. 8).

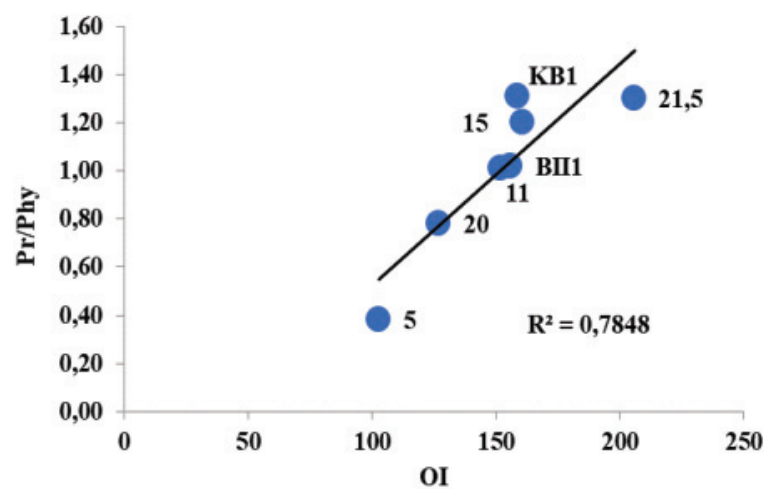

Puс.6 Линейная зависимость параметров пристан/фитан (Pr/Phy) и кислородного индекса (OI)

Fig. 6. Linear correlation of the Pristan/Phytan (Pr/Phy) ratio and Oxygen Index (OI)

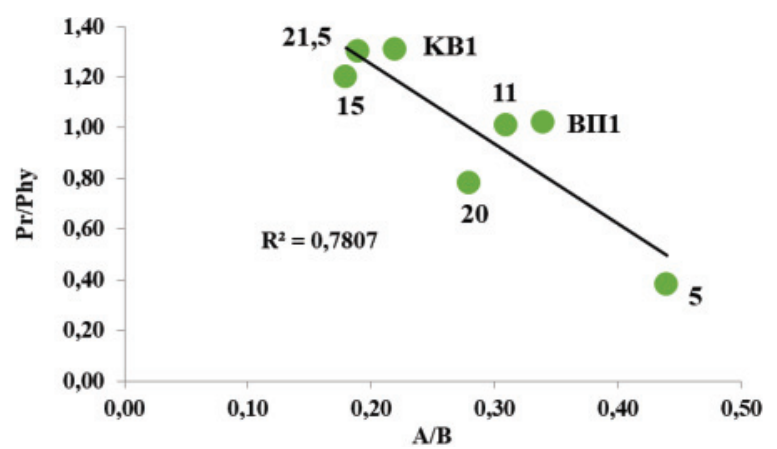

Рис. 7. Взаимосвязь параметров пристан/фитан и $A / B$

Fig. 7. Correlation of $\mathrm{Pr} / \mathrm{Phy}$ and $\mathrm{A} / \mathrm{B}$ ratios

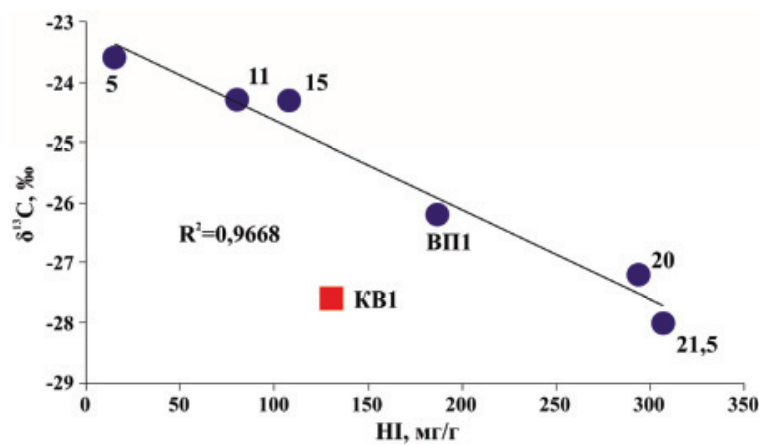

Pис. 8. Зависилость водородного показателя от изотопного со става $C_{\text {орг }}$ осадков

Fig. 8. Correlation of Hydrogen Index (HI) and A/B ratio 
Вследствие обрушения осадочных пород с верхних горизонтов органическое вещество в конусе выноса является смешанным, то есть содержит в себе как глубоко окисленное, так и слабо преобразованное.

Вполне вероятно, что накопление ОВ на уровне 11 м в прошлом происходило в условиях волноприбойной зоны. При понижении уровня моря имело место интенсивное окисление ОВ осадков, которое привело к потере в его составе насыщенных структурных фрагментов, в результате чего на уровне 5,0 м осталось небольшое количество ОВ, представленного в основном конденсированными структурами (табл. 3 , рис. 8).

\section{Заключение}

Графики зависимостей, представленные на рис. 6-8, показывают очень хорошую сопоставимость результатов, полученных разными методами исследования (Rock-Eval, XMC изотопия углерода), что обусловлено особенностями состава органиче-

\section{СПИСОК ЛИТЕРАТУРЫ}

1. Отчет Межправительственной группы экспертов по изменениям климата, 2007. - М.: МГЭИК, 2007. URL: http:// www.ipcc.ch/pdf/assessment-report/ar4/syr/ar4_syr_ru.pdf (дата обращения 02.04.2018).

2. Kattsov V.M., Källén E. Ch. 4: Future climate change: modeling and scenarios // Arctic Climate Impact Assessment (ACIA). Impacts of a warming arctic. - 2005. - P. 99-150. URL: https://www.amap.no/documents/download/1085/inline (дата обращения 02.04.2018)

3. Shakhova N., Semiletov I. Methane Hydrate Feedbacks // Arctic Climate Feedbacks: Global Implications. - USA: WWF International Arctic Programme, 2009. - P. 81-92.

4. Central Arctic Ocean paleoceanography from $\sim 50$ ka to present on the basis of ostracode faunal assemblages from the SWERUS 2014 expedition / L. Gemery, T.M. Cronin, R.K. Poirier, C. Pearce, N. Barrientos, M. O'Regan, C. Johansson, A. Koshurnikov, M. Jakobsson // Climate of the Past. - 2017. - V. 13. P. $1473-1489$

5. Pore water geochemistry along continental slopes north of the East Siberian Sea: inference of low methane concentrations / C.M. Miller, G.R. Dickens, M. Jakobsson, C. Johansson, A. Koshurnikov, M. 0'Regan, F. Muschitiello, C. Stranne, C. Mörth // Biogeosciences. - 2017. - V. 14. - P. 2929-2953.

6. Vetrov A.A., Romankevich E.A. Carbon Cycle in the Russian Arctic Seas. - Berlin: Springer, 2004. - 331 p.

7. Current rates and mechanisms of subsea permafrost degradation in the East Siberian Arctic Shelf / N. Shakhova, I. Semiletov, 0. Gustafsson, V. Sergienko, L. Lobkovsky, 0. Dudarev, T. Tumskoy, M. Grigoriev, A. Mazurov, A. Salyuk, R. Ananiev, A. Koshurnikov, D. Kosmach, A. Charkin, N. Dmitrevsky, V. Karnaukh, A. Gunar, A. Meluzov, D. Chernykh // Nature Communications. - 2017. - V. 8. DOI: 10.1038/ncomms 15872 .

8. Сорохтин Н.О., Лобковский Л.И., Семилетов И.П. Глубинный цикл углерода и формирование абиогенных углеводородов // Известия Томского политехнического университета. Инжиниринг георесурсов. - 2018. - Т. 329. - № 8. - С. 156-173.

9. Geochemical and geophysical evidence of methane release from the inner East Siberian Shelf / N. Shakhova, I. Semiletov, I. Leifer, P. Rekant, A. Salyuk, D. Kosmach // Journal of Geophysical Research. - 2010. - V. 115. - P. 187-193. ского вещества на молекулярном и изотопном уровнях. В свою очередь, они отражают комплекс биохимических и химических процессов, сопровождающих превращение OB на различных стадиях, начиная от раннего диагенеза и заканчивая разрушением OB при выходе пород на дневную поверхность.

Полученные результаты позволяют расширить представления об особенностях и закономерностях восточно-арктического литогенеза, выявить закономерности пространственной структуры распределения донных отложений, взвеси и элементноизотопного состава их органического вещества.

Работа выполнена при поддержке Правительства РФ (грант № 14.Z50.31.0012). Наталья Шахова и Олег Дударев благодарят Российский научный фонд (грант № 15-17-200-32-П) за поддержку их вклада в эту работу. Елена Гершелис также благодарна РФФИ за поддержку исследований, проводимых в рамках проекта 18-35-00572 Мол а. Авторы выражают признательность профессору Гончарову И.В. за ценные советы и практическую помощь, оказанные в процессе аналитических исследований и обсуждении полученных результатов.

10. Extensive methane venting to the atmosphere from sediments of the East Siberian Arctic Shelf / N. Shakhova, I. Semiletov, A. Salyuk, V. Joussupov, D. Kosmach, 0. Gustafsson // Science. 2010. - V. 327. - P. 1246-1250.

11. The origin of methane in the East Siberian Arctic Shelf unraveled with triple isotope analysis / C.J. Sapart, N. Shakhova, I. Semiletov, J. Jansen, S. Szidat, D. Kosmach, 0. Dudarev, C. van der Veen, M. Egger, V. Sergienko, A. Salyuk, V. Tumskoy, J.-L. Tison, T. Roeckmann // Biogeosciences. - 2017. - V. 14. P. 2283-2292.

12. Sensitivity of the carbon cycle in the Arctic to climate change / A.D. McGuire, L.G. Anderson, T.R. Christensen, S. Dallimore, L. Guo, D.J. Haye, M. Heimann, T.D. Lorenson, R.W. Macdonald, N. Roulet // Ecological Monographs. - 2009. - V. 79. P. 523-555. DOI: $10.1890 / 08-2025.1$.

13. Brunauer S., Emmett P.H., Teller E. Adsorption of gases in multimolecular layers // Journal of the American Chemical Society. - 1938. - V. 60. - P. 309-319.

14. Problems of arctic shelf research: the experience from integrated geologic and geochemical studies in the Laptev sea / A.S. Ulyantsev, L.I. Lobkovsky, A.V. Zhavoronkov, E.A. Romankevich // Oceanology. - 2015. - V. 55. - № 6. - P. 919-925.

15. Composition and fate of terrigenous organic matter along the Arctic land-ocean continuum in East Siberia: Insights from biomarkers and carbon isotopes / T. Tesi, I. Semiletov, G. Hugelius, 0. Dudarev, P. Kuhry, 0. Gustafsson // Geochimica et Cosmochimica Acta. - 2014. - V. 133. - P. 235-256.

16. Preferential burial of permafrost-derived organic carbon in Siberian - Arctic shelf waters / J.E. Vonk, I.P. Semiletov, O.V. Dudarev, T.I. Eglington, A. Andersson, N. Shakhova, A. Charkin, B. Heim, 0. Gustafsson // Journal of Geophysical Research. 2014. - V. 119. - № 12. - P. 8410-8421.

17. Деградация подводной мерзлоты и разрушение гидратов шельфа морей восточной арктики как возможная причина «метановой катастрофы»: некоторые результаты комплексных исследований 2011 года / В.И. Сергиенко, Л.И. Лобковский, И.П. Семилетов, О.В. Дударев, Н.Н. Дмитревский, Н.Е. Шахова, Н.Н. Романовский, Д.А. Космач, Д.Н. Никольский, С.Л. Никифоров, А.С. Саломатин, Р.А. Ананьев, А.Г. Росляков, А.Н. Салюк, В.В. Карнаух, Д.Б. Черных, В.Е. Тумской, В.И. Юсупов, А.В. Куриленко, Е.М. Чувилин, Б.А. Буханов // 
Доклады Академии Наук. - 2012. - Т. 446. - № 3. C. $330-335$.

18. Vetrov A.A., Romankevich E.A. Interannual variability of the primary production and organic carbon fluxes in the Arctic seas of Russia // Oceanology. - 2008. - V. 48. - № 3. - P. 340-348.

19. Mayer L.M. Surface-area control of organic-carbon accumulation in continental-shelf sediments // Geochimica et Cosmochimica Acta. - 1994. - V. 58. - P. 1271-1284.

20. Ice-shelf damming in the glacial Arctic Ocean: dynamical regimes of a basin-covering kilometre-thick ice shelf / J. Nilsson, M. Jakobsson, C. Borstad, N. Kirchner, G. Björk, R.T. Pierrehumbert, C. Stranne // The Cryosphere. - 2017. - V. 11. - P. 1745-1765.

21. Pugach S.P., Pipko I.I. Dynamics of colored dissolved matter on the East Siberian sea shelf // Doklady Earth Sciences. - 2013. V. 448. - № 1. - P. 153-156.

22. Yedoma Ice Complex of the Buor Khaya Pen insula (southern Laptev Sea) / L. Schirrmeister, G. Schwamborn, P.P. Overduin, J. Strauss, M.C. Fuchs, M. Grigoriev, I. Yakshina, J. Rethemeyer, E. Dietze, S. Wetterich // Biogeosciences. - 2017. - V. 14. P. 1261-1283.

23. Sorptive preservation of labile organic-matter in marine sediment / R.G. Keil, D.B. Montlucon, F.G. Prahl, J.I. Hedges // Nature. 1994. - V. 370 (6490). - P. 549-552.

24. Баффингтон Р., Уилсон М. Детекторы для газовой хроматографии / Пер. с нем. - М.: Мир, 1993. - 80 с.

25. Mass-spectra of pentacyclic triterpenoids / K. Shiojima, Y. Arai, K. Masuda, Y. Takase, T. Ageta, H. Ageta // Chemical and Pharmaceutical Bulletin. - 1992. - V. 40. - № 7. - P. 1683-1690.

26. NMR-spectra of triterpenoids. II. Hopenes and migrated hopenes / H. Ageta, K. Shiojima, Y. Arai, H. Suzuki, T. Kiyotani // Chemical and Pharmaceutical Bulletin. - 1994. - V. 42. - P. 39-44.

27. Dependence of composition of asphaltene-resin-wax deposits on the water cut value / E.V. Kirbizhekova, I.V. Prozorova, N.A. Nebogina, N.V. Yudina, A.A. Grin'ko // Petroleum Chemistry. - 2016. - V. 56. - № 8. - P. 765-770.

28. Peters K.E., Walters C.C., Moldowan J.M. The Biomarker Guide. $2^{\text {nd }}$ ed. P. I. Biomarkers and Isotopes in the Environmental and Human History. - Cambridge: Cambridge University Press, 2005. $-387 \mathrm{p}$.

\section{Информация об авторах}

Перевертайло T.Г., кандидат геолого-минералогических наук, доцент отделения геологии Инженерной школы природных ресурсов Национального исследовательского Томского политехнического университета.

Кажулуханова М.З., геолог, ГИС-специалист ТОО «Казцинк» .

Недоливко Н.М., кандидат геолого-минералогических наук, доцент отделения геологии Инженерной школы природных ресурсов Национального исследовательского Томского политехнического университета.

Гринько A.A., кандидат химических наук, научный сотрудник Международной научно-образовательной лаборатории изучения углерода арктических морей Инженерной школы природных ресурсов Национального исследовательского Томского политехнического университета.

Шахова H.E., доктор геолого-минералогических наук, ведущий научный сотрудник Международной научнообразовательной лаборатории изучения углерода арктических морей Инженерной школы природных ресурсов Национального исследовательского Томского политехнического университета.

Дударев О.В., доктор геолого-минералогических наук, ведущий научный сотрудник Лаборатории арктических исследований Тихоокеанского океанологического института им. В.И. Ильичева Дальневосточного отделения Российской Академии наук; научный сотрудник Международной научно-образовательной лаборатории изучения углерода арктических морей Инженерной школы природных ресурсов Национального исследовательского Томского политехнического университета.

Гершелис $\boldsymbol{E}$.B., ассистент отделения геологии Инженерной школы природных ресурсов Национального исследовательского Национального исследовательского Томского политехнического университета. 
Мазуров A.א., доктор геолого-минералогических наук, профессор отделения геологии Инженерной школы природных ресурсов Национального исследовательского Томского политехнического университет.

Семилетов И.П., доктор географических наук, член-корреспондент Российской Академии наук, заведующий Лабораторией арктических исследований Тихоокеанского океанологического института им. В.И. Ильичева Дальневосточного отделения Российской Академии наук; профессор Международной научно-образовательной лаборатории изучения углерода арктических морей Инженерной школы природных ресурсов Национального исследовательского Томского политехнического университета. 
UDC 552.5(263.53)

\section{LITHOLOGICAL FEATURES AND ORGANIC MATTER OF SEDIMENTS IN THE SOUTH-EASTERN LAPTEV SEA (MUOSTAKH CAPE)}

\section{Tatyana G. Perevertaylo', ptg@tpu.ru}

\author{
Malika Z. Kazhumukhanova², \\ kazhumukhanova@gmail.com
}

\section{Natalya V. Nedolivko',} nedolivko@tpu.ru

Andrey A. Grinko', grinko@tpu.ru

\author{
Natalia E. Shakhova', \\ shahova@tpu.ru \\ 1 National Research Tomsk Polytechnic University, \\ 30, Lenin Avenue, Tomsk, 634050, Russia. \\ 2 LLP «KazZinc», \\ 96, Abaya Street, Kokshetau, 020000, Kazakhstan. \\ ${ }^{3}$ Pacific Oceanological Institute, Russian Academy of Sciences, \\ 43, Baltiyskaya street, Vladivostok, 690041, Russia.
}

Oleg V. Dudarev ${ }^{3,1}$ dudarev@poi.dvo.ru

Elena V. Gershelis', elenapanova@tpu.ru

\author{
Alexey K. Mazurov', \\ akm@tpu.ru \\ Igor P. Semiletov ${ }^{3,1}$, \\ ipsemiletov@alaska.edu
}

The present study seeks to improve current understanding of modern climate changes, which are considered as the consequences of the greenhouse effect caused by increasing content of the main greenhouse gases - carbon dioxide and methane. Complex studies in the land-shelf-atmosphere system across the Arctic shelf, including biogeochemical and lithological analyses of sediments across Eastern Arctic seas, are needed.

The research aims to study both lithological and mineralogical sediment compositions, variability of the organic matter content $\left(C_{\text {org }}\right)$, molecular and isotopic composition of carbon ( $\delta 13 C$ ) contained in the ice complex deposits (ICD) along the Laptev Sea coast (Cape Muostakh). Samples of modern bottom sediments obtained during the expedition of 2015 in the south-eastern part of the Laptev Sea were investigated.

Methods used in the present study include GC-MS analysis, pyrolysis, isotope analysis, X-ray phase analysis followed by further numerical processing and interpretation.

Results. The mineralogical composition of the clay fraction has been studied, and the distribution of clay minerals has been established. The features of molecular and isotopic $C_{\text {org }}$ composition are revealed. Initial results on the hydrocarbon source of ICD- $C_{\text {org, }}$ which dominates in the shallow part of the East Siberian Arctic shelf, are obtained. Pyrolysis and GC-MS data are highly correlated reflecting complex biogeochemical processes occurring during the $C_{\text {org }}$ transformation at the various stages of lithogenesis. In addition, the study provides preliminary estimates of the light hydrocarbons generation potential for the $C_{\text {org }}$ contained in the sediments.

\section{Key words:}

Organic matter, bottom sediments, isotope analysis, GC-MS, mineralogical composition, Laptev Sea, Cape Muostakh.

The research was supported by the Government of the RF (grant no. 14.Z50.31.0012). Natalya Shakhova and Oleg Dudarev appreciate the support and contribution of the research of the Russian Science Fund (grant no. 15-17-200-32-I). Elena Gershelis appreciates the support of the research within the project 18-35-00572 Мол_a of the RFBR. The authors express thanks to professor I.V. Goncharov for valuable advice and practical aid in analytical studies and discussion of the results obtained.

\section{REFERENCES}

1. Otchet Mezhpravitelstvennoy gruppy ekspertov po izmeneniyam klimata [Report of the Intergovernmental Panel on Climate Change]. Moscow, MGEIK 2007. 52 p. Available at: http:// www.ipcc.ch/pdf/assessment-report/ar4/syr/ar4_syr_ru.pdf (accessed 02 April 2018).

2. Ch. 4: Future climate change: modeling and scenarios. Arctic Climate Impact Assessment. Impacts of a warming arctic, 2005, pp. 99-150. Available at: https://www.amap.no/documents/ download/1085/inline (accessed 02 April 2018).
3. Shakhova N., Semiletov I. Methane Hydrate Feedbacks. Arctic Climate Feedbacks: Global Implications. USA, WWF International Arctic Programme, 2009. pp. 81-92.

4. Gemery L., Cronin T.M., Poirier R.K., Pearce C., Barrientos N., 0'Regan M., Johansson C., Koshurnikov A., Jakobsson M. Central Arctic Ocean paleoceanography from $\sim 50$ ka to present, on the basis of ostracode faunal assemblages from the SWERUS 2014 expedition. Climate of the Past, 2017, vol. 13, pp. 1473-1489.

5. Miller C.M., Dickens G.R., Jakobsson M., Johansson C., Koshurnikov A., O'Regan M., Muschitiello F., Stranne C., Mörth C. Po- 
re water geochemistry along continental slopes north of the East Siberian Sea: inference of low methane concentrations. Biogeosci ences, 2017, vol. 14, pp. 2929-2953.

6. Vetrov A.A., Romankevich E.A. Carbon Cycle in the Russian Ar ctic Seas. Berlin, Springer, 2004. 331 p

7. Shakhova N., Semiletov I., Gustafsson 0., Sergienko V., Lobkovsky L., Dudarev 0., Tumskoy T., Grigoriev M., Mazurov A., Salyuk A., Ananiev R., Koshurnikov A., Kosmach D., Charkin A., Dmitrevsky N., Karnaukh V., Gunar A., Meluzov A., Chernykh D. Current rates and mechanisms of subsea permafrost degradation in the East Siberian Arctic Shelf. Nature Communications, 2017, vol. 8. DOI: 10.1038/ncomms15872.

8. Sorokhtin N.0., Lobkovsky L.I., Semiletov I.P. Carbon depth cycle and formation of abiogenic hydrocarbons. Bulletin of the Tomsk Polytechnic University. Geo Assets Engineering, 2018, vol. 329 , no. 8, pp. 156-173. In Rus.

9. Shakhova N., Semiletov I., Leifer I., Rekant P., Salyuk A., Kosmach D. Geochemical and geophysical evidence of methane release from the inner East Siberian Shelf. Journal of Geophysical Research, 2010, vol. 115, pp. 187-193.

10. Shakhova N., Semiletov I., Salyuk A., Joussupov V., Kosmach D., Gustafsson 0. Extensive methane venting to the atmosphere from sediments of the East Siberian Arctic Shelf. Science, 2010, vol. 327 , pp. 1246-1250.

11. Sapart C.J., Shakhova N., Semiletov I., Jansen J., Szidat S., Kosmach D., Dudarev 0., Van der Veen C., Egger M., Sergienko V., Salyuk A., Tumskoy V., Tison J.-L., Roeckmann T. The origin of methane in the East Siberian Arctic Shelf unraveled with triple isotope analysis. Biogeosciences, 2017, vol. 14, pp. 2283-2292.

12. McGuire A.D., Anderson L.G., Christensen T.R., Dallimore S., Guo L., Hayes D.J., Heimann M., Lorenson T.D., Macdonald R.W., Roulet N. Sensitivity of the carbon cycle in the Arctic to climate change. Ecological Monographs, 2009, vol. 79, no. 4, pp. 523-555. DOI: 10.1890/08-2025.1.

13. Brunauer S., Emmett P.H., Teller E. Adsorption of gases in multimolecular layers. Journal of the American Chemical Society, 1938, vol. 60, pp. 309-319.

14. Ulyantsev A.S., Lobkovsky L.I., Zhavoronkov A.V., Romankevich E.A. Problems of arctic shelf research: the experience from integrated geologic and geochemical studies in the Laptev sea. Oceanology, 2015, vol. 55, no. 6, pp. 919-925.

15. Tesi T., Semiletov I., Hugelius G., Dudarev 0., Kuhry P., Gustafsson 0. Composition and fate of terrigenous organic matter along the Arctic land-ocean continuum in East Siberia: Insights from biomarkers and carbon isotopes. Geochimica et Cosmochimica Acta, 2014, vol.133, pp. 235-256.

16. Vonk J.E., Semiletov I.P., Dudarev 0.V., Eglington T.I., Andersson A., Shakhova N., Charkin A., Heim B., Gustafsson 0. Preferential burial of permafrost-derived organic carbon in Siberian Arctic shelf waters. Journal of Geophysical Research, 2014, vol. 119 , no. 12, pp. 8410-8421.

17. Sergienko V.I., Lobkovskii L.I., Semiletov I.P., Dudarev 0.V., Dmitrievskii N.N., Shakhova N.E., Romanovskii N.N., Kosmach D.A., Nikolskii D.N., Nikiforov S.L., Salomatin A.S., Anan'ev R.A., Roslyakov A.G., Salyuk A.N., Karnaukh V.V., Chernykh D.B., Tumskoi V.E., Yusupov V.I., Kurilenko A.V., Chuvilin E.M., Buhanov B.A. The degradation of submarine permafrost and the destruction of hydrates on the shelf of Eastern Arctic seas as a potential cause of the "methane catastrophe»: some results of integrated studies in 2011. Doklady Earth Sciences, 2012, vol. 446, no. 1, pp. 1132-1137.

18. Vetrov A.A., Romankevich E.A. Interannual variability of the primary production and organic carbon fluxes in the Arctic seas of Russia. Oceanology, 2008, vol. 48, no. 3, pp. 340-348.

19. Mayer L.M. Surface-area control of organic-carbon accumulation in continental-shelf sediments. Geochimica et Cosmochimica Ac ta, 1994, vol. 58, pp. 1271-1284.
20. Nilsson J., Jakobsson M., Borstad C., Kirchner N., Björk G., Pierrehumbert R.T., Stranne C. Ice-shelf damming in the glacial Arctic Ocean: dynamical regimes of a basin-covering kilometrethick ice shelf. The Cryosphere, 2017, vol. 11, pp. 1745-1765.

21. Pugach S.P., Pipko I.I. Dynamics of colored dissolved matter on the East Siberian sea shelf. Doklady Earth Sciences, 2013, vol. 448 , no. 1, pp. 153-156.

22. Schirrmeister L., Schwamborn G., Overduin P.P., Strauss J., Fuchs M.C., Grigoriev M., Yakshina I., Rethemeyer J., Dietze E., Wetterich S. Yedoma Ice Complex of the Buor Khaya Peninsula (southern Laptev Sea). Biogeosciences, 2017, vol. 14, pp. 1261-1283.

23. Keil R.G., Montlucon D.B., Prahl F.G., Hedges J.I. Sorptive preservation of labile organic-matter in marine sediment. Nature, 1994, vol. 370 (6490), pp. 549-552.

24. Buffington R., Wilson M. Detectors for gas chromatography. Translated from German. Moscow, Mir Publ., 1993.80 p.

25. Shiojima K., Arai Y., Masuda K., Takase Y., Ageta T., Ageta H. Mass-spectra of pentacyclic triterpenoids. Chemical and Pharmaceutical Bulletin, 1992, vol. 40, no. 7, pp. 1683-1690.

26. Ageta H., Shiojima K., Arai Y., Suzuki H., Kiyotani T. NMRspectra of triterpenoids. 2. Hopenes and migrated hopenes. Chemical and Pharmaceutical Bulletin, 1994, vol. 42, pp. 39-44.

27. Kirbizhekova E.V., Prozorova I.V., Nebogina N.A., Yudina N.V., Grin'ko A.A. Dependence of composition of asphaltene-resin-wax deposits on the water cut value. Petroleum Chemistry, 2016, vol. 56 , no. 8, pp. 765-770.

28. Peters K.E., Walters C.C., Moldowan J.M. The Biomarker Guide. $2^{\text {nd }}$ ed. P. I. «Biomarkers and Isotopes in the Environmental and Human History». Cambridge, Cambridge University Press Publ., 2005. $387 \mathrm{p}$.

29. Peters K.E. Guidelines for evaluating petroleum source rock using programmed pyrolysis. American Association of Petroleum Geologists, 1986, vol. 70, pp. 318-329.

30. Rock-Eval 6 Turbo. User Guide. Vinci Technologies, 2013.

31. Kashapov R.S., Goncharov I.V., Samoylenko V.V., Oblasov N.V., Trushkov P.V. Accuracy of ROCK-EVAL method. International journal of applied and fundamental research, 2015, no. 10, pp. 866-873. In Rus.

32. Chakhmakhchev A., Sampei Y., Suzuki N. Geochemical characteristics of oils and source rocks in the Yamal Peninsula, West Siberia, Russia. Organic Geochemistry, 1994, vol. 22, no. 2, pp. 311-322.

33. Moore D.M., Reynolds R.C. Jr. X-ray Diffraction and the Identification and Analysis of Clay Minerals. Oxford, Oxford University Press Publ., 1997. 548 p.

34. Shaldybin M.V. "Clay» in sandstone: origin, composition, evolution (review of foreign articles). Geology, Geophysics and Development of Oil and Gas Fields, 2015, no. 1, pp. 58-69. In Rus.

35. Hillier S. Quantitative analysis of clay and other minerals in sandstones by X-ray Powder Diffraction (XRPD). International Association of Sedimentologists Special Publication, 2003, vol. 34, pp. 213-251.

36. Tarnocai C., Canadell J.G., Schuur E.A.G., Kuhry P., Mazhitova G., Zimov S. Soil organic carbon pools in the northern circumpolar permafrost region. Global Biogeochemical Cycles, 2009, vol. 23, GB2023. DOI: 10.1029/2008GB003327.

37. Grigoriev M.N., Razumov S.O., Kunitzkiy V.V., Spektor V.B. Dynamics of the Russian East Arctic Sea coast: major factors, regularities and tendencies. Earth Cryosphere, 2006, vol. 10, no. 4, pp. 74-94. In Rus.

38. Chakhmakhchev V.A., Vinogradova T.L. Geokhimicheskie pokazateli fatsialno-gebeticheskikh tipov iskhodnogo organicheskogo veshchestva [Geochemical indicators of facies and genetic types of parent organic matter]. Geochemistry International, 2003, vol. 41, no. 5 , pp. 497-502. 


\section{Information about the authors}

Tatyana G. Perevertaylo, Cand. Sc., associate professor, National Research Tomsk Polytechnic University.

Malika Z. Kazhumukhanova, geologist, GIS-specialist, LLP «KazZinc».

Natalya V. Nedolivko, Cand. Sc., associate professor, National Research Tomsk Polytechnic University.

Andrey A. Grinko, Cand. Sc., researcher, National Research Tomsk Polytechnic University.

Natalia E. Shakhova, Dr. Sc., leading researcher, National Research Tomsk Polytechnic University.

Oleg V. Dudarev, Dr. Sc., leading researcher, Pacific Oceanological Institute, Russian Academy of Sciences; researcher, National Research Tomsk Polytechnic University.

Elena V. Gershelis, assistant, National Research Tomsk Polytechnic University.

Alexey K. Mazurov, Dr. Sc., professor, National Research Tomsk Polytechnic University.

Igor P. Semiletov, Dr. Sc., correspondent-member, head of the laboratory, Pacific Oceanological Institute, Russian Academy of Sciences; professor, National Research Tomsk Polytechnic University. 